\title{
Variation in positive surgical margin status following radical prostatectomy for pT2 prostate cancer
}

Wei Shen Tan, MD, MRCS ${ }^{1,2,3}$, Marieke J Krimphove, MD ${ }^{1,4}$, Alexander P. Cole, MD1, Maya Marchese, MS¹, Sebastian Berg, MD ${ }^{1,5}$, Stuart R Lipsitz, SCD ${ }^{1}$, Björn Löppenberg, $\mathrm{MD}^{5}$, Junaid Nabi, MD, MPH${ }^{1}$, Firas Abdollah, MD, FEBU 6 , Toni $\mathrm{K}$. Choueiri, MD7, Adam S. Kibel, MD1, Prasanna Sooriakumaran, MD, PhD, FRCS $(\text { Urol) })^{2,3}$, Quoc-Dien Trinh, MD ${ }^{1,7 *}$

1. Center for Surgery and Public Health, Division of Urological Surgery, Brigham and Women's Hospital, Harvard Medical School, Boston, MA, USA

2. Division of Surgery \& Interventional Science, University College London, London, UK

3. Department of Urology, University College London Hospitals, London, UK

4. Department of Urology, University hospital Frankfurt, Frankfurt am Main, Germany

5. Department of Urology and Neurourology, Marien Hospital Herne, RuhrUniversity Bochum, Herne, Germany.

6. Vattikuti Urology Institute, Henry Ford Hospital, Detroit, MI, USA

7. Lank Center for Genitourinary Oncology, Dana-Farber/Brigham and Women's Cancer Center, Harvard Medical School, Boston, MA, USA

${ }^{*}$ Corresponding Author:

Quoc-Dien Trinh, MD

Center for Surgery and Public Health,

Division of Urological Surgery,

Brigham and Women's Hospital,

Harvard Medical School,

45 Francis St, ASB II-3,

Boston, MA 02115

Email: qtrinh@bwh.harvard.edu

Word count: 2431 
39 Conflict of interest statement: Authors declare no conflict of interest. The National 40 Cancer Data Base (NCDB) is a joint project of the Commission on Cancer (CoC) of

MicroAbstract (56/60 words)

Positive surgical margin (PSM) following prostatectomy for pT2 prostate cancer vary throughout the USA. We utilized the National Cancer Database and determined that patient, hospital and cancer-specific factors contributed $2.3 \%, 3.9 \%$ and $15.6 \%$ of PSM variation respectively. $84.8 \%$ of PSM variation are due to non-oncological factors which represent addressable factors in efforts to improve patient outcome.

3

4

55

6


Abstract (249/250 words)

Introduction

We evaluated patient, hospital, and cancer-specific factors associated with positive surgical margin (PSM) variability following radical prostatectomy in pT2 prostate cancer in the USA.

Material \& Methods

A total of 45,426 men from 1,152 hospitals with pT2 prostate cancer and known margin status following radical prostatectomy were identified using the National Cancer Database (2010-2015). Patient, cancer, hospital factors and surgical approach were extracted. A mixed effects logistic regression model was computed to examine factors associated with PSM and partial- $\mathrm{R}^{2}$ values to assess the relative contributions of patient, cancer and hospital variables to PSM status.

Results

Median PSM rate of 8.5\% (IQR: 5.2-13.0\%). Robotic (OR: 0.90, 95\% Cl: 0.83-0.99) and laparoscopic (OR: 0.74, 95\% Cl: 0.64-0.90) surgical approach, academic institution (OR: 0.87, 95\% Cl: 0.76-1.00) and high hospital surgical volume (>297 cases [OR: $0.83,95 \% \mathrm{Cl}$ : 0.70-0.99) were independently associated with a lower PSM. Black men (OR: 1.13, 95\% Cl: 1.01-1.26) and adverse cancer specific features (PSA 10-20, PSA >20, cT3 stage, Gleason 7, 8, 9-10; all p>0.01) were independently associated with a higher PSM. Patient-specific, hospital-specific and cancer-specific factors had a contribution of $2.3 \%, 3.9 \%$ and $15.6 \%$ to the variation in PSM. Facility had a contribution of $23.7 \%$ to the variation in PSM.

\section{Conclusion}

Cancer-specific factors account for $15.2 \%$ of PSM variation with the remaining $84.8 \%$ of PSM variation due to patient, hospital and other factors not accounted within the model. Non-cancer-specific factors represent addressable factors which are important for policy makers in efforts to improve patient outcome.

Keywords: localized; prostate cancer; practice patterns; radical prostatectomy; surgical margin; variation 
Introduction

Oncological principles of cancer surgery advocate complete excision of the cancer with negative surgical margins. In localised prostate cancer, the management of positive surgical margins (PSM) following radical prostatectomy remains controversial. PSM has been associated with a two-fold increased risk of biochemical recurrence although this has not been translated to cancer specific survival with long term follow-up., 2

PSM following radical prostatectomy for pT2 prostate cancer is considered a metric for surgical quality. ${ }^{3}$ However, there is significant variation in PSM rates reported in the literature. ${ }^{1,4}$ Cancer specific risk factors for PSM following radical prostatectomy are well established. There is a clear stage correlation with risk of PSM where pT3 cancers report a PSM of as high as $29-50 \%$ compared to the $4-23 \%$ in pT2 cancers. ${ }^{5}$ Inaccurate clinical staging based on pre-surgery magnetic resonance imaging (MRI) leading to the decision for nerve-sparing can be associated with a risk for PSM. ${ }^{6}$ Surgical technique, surgeon's preference for a nerve-sparing approach and attempts to preserve maximal urethral length are factors affecting PSM rates. ${ }^{7,8}$ Anatomical location of cancer within the prostate can be a risk factor, where apical cancers in particular have a higher risk of PSM because the lack of a distinct capsule and high anatomical variability of the apex. ${ }^{1}$

What remains less clear is non-cancer specific risk factors. Reports have shown an association between higher surgeon operating volume and lower PSM rates. ${ }^{7}$ However, PSM rates between open and robotic techniques are comparable. ${ }^{9}$ Cancer specific factors and surgeon volume alone cannot account for the large variation in PSM. Significant variation in the management of prostate cancer has been widely reported. Variations in active surveillance and treatment outcomes for prostate cancer have been demonstrated. ${ }^{10,} 11$ We hypothesised that other factors such as patient demographics, socioeconomic, geographic and surgical approach may have an association with PSM.

In this study, we sought to examine contemporary PSM rates in the United States using the National Cancer Data Base (NCDB) registry. ${ }^{12}$ We used a multivariable mixed-effects model to estimate the association between PSM and patient demographics, socioeconomic, geographical, hospital, cancer-specific and surgical 
Prepared for Clinical Genitourinary Cancer

128

129

130

131

132

133

134

135

136

137

138

139

140

141

142

143

144

145

146

147

148

149

150

151

152

approach factors. We then derived the corresponding contribution of each factor to variation in PSM.

\section{0}

1

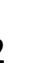

3

4

35

36

7


Material and methods

Data source

We queried the NCDB, which represents a nationwide oncology database that contains details on cancer care and treatment outcomes across CoC hospital. Since 1989, all newly diagnosed cancers from 1,500 CoC-accredited programmes in the United States and Puerto Rico have been captured by the NCDB. This accounts for over 29 million cancer cases which represents over $50 \%$ of all newly diagnosed prostate cancer cases in the United States. ${ }^{13}$

\section{Patient selection}

All men diagnosed with prostate cancer between 2010-2015 treated with radical prostatectomy for adenocarcinoma of the prostate (code C61.9 from International Classification of Diseases for Oncology, 3rd edition) ${ }^{14}$ according to National Comprehensive Cancer Network (NCCN) guidelines ${ }^{15}$ were included for analysis. Patients with PT2NOMO cancer were selected based on AJCC Cancer Staging Manual ( $7^{\text {th }}$ edition). ${ }^{16}$ Patients with unknown status of histological margin were excluded.

\section{Variable of interest and covariates}

PSM was defined as NCDB variable "RX_SUMM_SURGICAL_MARGINS". Baseline patient specific variables include: patient age at diagnosis (categorised by quartiles: 40-57, 58-62, 63-67 or 68-75 years), prostate-specific antigen (PSA) at prostate cancer diagnosis (continuous), Gleason score $(\leq 6,7,8,9,10)$, clinical T stage (cT1, CT2, cT3, cT4), race (Black, White, other), Charlson Comorbidity Index [CCI] $(0,1$, $\geq 2$ ) and year of diagnosis $(2010,2011,2012,2013,2014,2015)$. Socioeconomic variables include: insurance status (private, Medicaid, Medicare, other government [including TRICARE, Military, VA and Indian/ Public Health Service], uninsured), median household income within the ZIP code $(\leq \$ 37,999, \$ 38,000-\$ 47,999$, $\$ 48,000-\$ 62,999$, or $\geq \$ 63,000$ ) and median proportion of individuals within the ZIP code without a high school diploma ( $\leq 6.9 \%, 7 \%-12.9 \%, 13 \%-20.9 \%$, or $\geq 21 \%)$. 
Geographical and treating hospital variables include: urban/rural status (metropolitan, urban county, rural county), great circle distance $(<6.3,6.3-13.9,14-$ 35.6, $>35.6$ miles between a patient's residence based on the ZIP code centroid or city and the street address of the facility), census geographical region (New England, Middle Atlantic, South Atlantic, East North Central, East South Central, West North Central, West South Central, Mountain, or Pacific), type of treating hospital (community cancer program, comprehensive community cancer program, academic/ research programme, integrated network cancer programme) and hospital annual surgical volume according to quartiles (<89 cases, 89-164 cases, 164-296 cases, $>297$ cases). Surgical approach was defined as open, laparoscopic or robotic.

\section{Statistical analysis}

For descriptive statistics, frequency and proportions were used to report categorical variables and medians and interquartile ranges (IQR) were used to report continuous variables. Chi-square and Wilcoxon tests were used to analyse bivariate differences in categorical and continuous variables between patient groups respectively. To account for clustering within treating hospitals we used a random effect model and accounted for individual treating hospital. ${ }^{17,18}$

A mixed effects logistic regression model was performed to predict the odds of a patient having a PSM following prostatectomy with treating hospital considered as a random effect. Fixed covariables included patient-specific factors (age, $\mathrm{CCl}$, race, socioeconomic factors [education, income, insurance status], urban/ rural locality, great circle distance), cancer-specific factors (PSA at diagnosis, Gleason score, clinical T stage). Hospital-specific factors (surgical approach, treating hospital type, geographical area, hospital surgical volume). Hospital were ranked from least-likely to most-likely to have a patient with PSM following prostatectomy and plotted against the probability of a PSM.

Using a mixed effects logistic regression model, partial- $R^{2}$ values were derived for each variable to assess the contributions of patient, hospital and cancer-specific variables to variation in PSM as previously described. ${ }^{11}, 19$ Partial $R^{2}$ represents the contribution of the variable to the variability in the probability of having a PSM and 
214 was computed by subtracting the pseudo- $\mathrm{R}^{2}$ value of the model without the variable 215 of interest from the pseudo- $R^{2}$ of the complete model.

216 Data analyses were performed using Stata 15 (StataCorp, College Station, Texas). 217 Statistical significance was defined as a 2 -sided significance with $p<0.05$. A waiver 218 was obtained before commencement of the study by the Brigham and Women's 219 Hospital Institutional review board in accordance with institutional regulation when using deidentified previously collected patient data. 
240

241

242

Results

Baseline characteristics

A total of 45,426 men from 1,152 CoC accredited hospital met the inclusion criteria. The median age for the entire cohort was 61 years (IQR: 56-66 years). Table 1 reports the baseline patient demographics and comorbidities, cancer-specific, socioeconomic, geographical and hospital specific variables. Black patients $(p=0.001)$, higher PSA $(p<0.001)$, higher clinical T stage $(p<0.001)$, higher Gleason score $(p<0.001)$, more recent year of diagnosis $(p=0.018)$, open surgical approach $(p<0.001)$, lower income $(p=0.006)$, higher education $(p<0.001)$, nearer great circle distance $(p<0.001)$, treatment at non-academic hospital $(p<0.001)$ and lower hospital surgical volume $(p<0.001)$ were associated with PSM on univariable analysis.

\section{Multivariate logistic regression analysis}

Independent factors associated with PSM were estimated using multivariable logistic regression as shown in Table 2. The only patient factor associated with a PSM was Black race (odds ratio [OR]: 1.13, 95\% confidence interval [Cl]: 1.01-1.26). Socioeconomic factors, rural/ urban county, great circle distance and comorbidity were not associated with PSM. Cancer-specific factors such as PSA of $10-20 \mathrm{ng} / \mathrm{mL}$ (OR: $1.18,95 \% \mathrm{Cl}: 1.05-1.32$ ), PSA of $>20 \mathrm{ng} / \mathrm{mL}$ (OR: $1.36,95 \% \mathrm{Cl}: 1.16-1.59$ ), CT3-4 stage (OR: 1.25, 95\% Cl: 1.14-2.17), Gleason score 7 (OR: 1.61, 95\% Cl: 14.9-1.73), 8 (OR: 1.48, 95\% Cl: 1.28-1.69) and 9-10 (OR: 1.80, 95\% Cl: 1.46-2.23) were independently associated with a higher odds of PSM. Hospital-specific factors independently associated with lower odds of PSM were robotic (OR: $0.90,95 \% \mathrm{Cl}$ : 0.83-0.99) and laparoscopic (OR: 0.74, 95\% Cl: 0.64-0.90) surgical approach, academic institution (OR: $0.87,95 \% \mathrm{Cl}: 0.76-1.00$ ), higher hospital surgical volume (>297 cases [OR: $0.83,95 \% \mathrm{Cl}: 0.70-0.99$ ) and East North Central USA (OR: 0.71 , $95 \% \mathrm{Cl}: 0.52-0.96)$. 
270 Variation in positive surgical margins

271 A total of 4,522 patients (11.1\%) had a PSM. The rate of PSM for cases performed 272 each year ranged from 9.1-11.0\% between 2010- 2015. The median PSM rate was $2738.5 \%$ (IQR: $5.2-13.0 \%$ ) with a PSM range of $0-100 \%$.

274 Figure 2 shows a caterpillar plot depicting the hospitals' adjusted risk of PSM ranked 275 from lowest to highest adjusted for patient demographics, cancer-specific, 276 socioeconomic, geographical and hospital specific variables. Partial- $\mathrm{R}^{2}$ - values 277 computed from the mixed effects logistic regression model for the investigated 278 variables are shown in Table 3. The overall model accounted for $24.9 \%$ of PSM 279 variation. Patient-specific, hospital-specific and cancer-specific factors contributed $2.3 \%, 3.9 \%$ and $15.2 \%$ of the variation in PSM in pT2 patients, respectively, that was unexplained by all of the other predictors. The individual facility, regardless of any other characteristics, explained $23.7 \%$ of the variation in PSM unexplained by the other predictors. 


\section{Discussion}

The key finding in this study is that there is significant variability in PSM rates following radical prostatectomy for pT2 prostate cancer. While cancer-specific variables such as Gleason score, clinical T stage and PSA at diagnosis are factors that influence the risk of PSM, non-cancer specific variables such as patient, hospital and surgical approach also account for variability in PSM even after adjustment in a multivariate model. In this study, we report that $2.3 \%$ and $3.9 \%$ of variation within the model are due to patient and hospital-specific factors while cancer-specific factors contributed $15.2 \%$ of PSM variation. Moreover, individual facility contributed $23.7 \%$ to the variability in the probability of having a PSM. While the sum of partial $R^{2}$ values can be above or below the total $\mathrm{R}^{2}$, their relative magnitude can be compared to assess additional explanatory power. This population-based study also found that the median PSM rate for pT2 prostate cancer in the United States is $8.5 \%$. This establishes a bench mark where poorer performing centres should strive to improve and highlights modifiable factors which can be addressed to improve patient outcome.

In an increasingly cost-conscious healthcare service, healthcare systems are shifting towards a pay-for-performance model. The traditional fee-for-service model reimburses healthcare providers based on quantity and complexity of services; in fact, subsequent procedures or complications are chargeable by the healthcare provider. Significant changes to bundled payments and pay-for-performance models promote high quality care as these improves efficiency within the service. However, often efforts to improve surgical outcome or medical service are multi-factorial and significant improvements represent the aggregation of marginal gains to achieve high quality outcome.

The median PSM rate in this study was 8.5\% (IQR: 5.2-13.0\%) which was lower compared to the 10.7-16.6\% reported in a systematic review of cases published between 2002-2010.4 The adoption of robotic prostatectomy may have indirectly led to the improvement in PSM rates by increased centralisation of care due to the high cost associated with the procurement of robotic technology. Indeed, between 2002 and 2010 , the number of surgeons performing radical prostatectomy fell from 10,000 surgeons to 8,200 and the proportion of high volume surgeons (performing $>24$ prostatectomies annually) increased from $10 \%$ to $45 \% .{ }^{20}$ It is widely reported that 
there is a strong correlation between surgical volume and risk of PSM. ${ }^{7}$ We observed this only in the top quartile of hospital surgical volume which may be explained by increased centralisation of care. This in turn results in an overall increase in surgical case load of remaining centres which makes differences in surgical proficiency less apparent.

We report that both robotic and laparoscopic prostatectomy had significantly lower PSM compared to open prostatectomy even after adjusting for cancer specific variables and hospital volume. However, there are variables that we could not account for. It is likely individual surgeons performing limited number of prostatectomies do not have access to the robotic platform and high-volume surgeons are more likely to perform radical prostatectomies robotically. Proponents for robotic prostatectomy might argue that a laparoscopic approach may allow better visualisation during apical dissection however, it is likely that PSM is influenced by individual surgical experience which we cannot account for in the NCDB. ${ }^{8,21}$

It is widely accepted that Black patients have worse cancer outcomes following radical prostatectomy even after adjusting for Gleason score and disease stage. ${ }^{22}$ However, the relationship between race and PSM is less certain. Previous retrospective studies have failed to find an association between race and PSM after controlling for cancer specific variables. ${ }^{23,24}$ More recently, Jalloh and colleagues studied 4,231 low risk prostate cancer patients treated with radical prostatectomy. ${ }^{25}$ After adjusting for clinical variables, year of diagnosis and clinical site they report that Black men were at a higher risk of having a PSM. This study did not adjust for hospital surgical volume and had a relatively small cohort of Black men $(n=273)$ of which, 22 men had a robotic approach. Our findings concur with what has been reported and even after adjustment with a multivariable model, the association between Black men and higher PSM was still apparent. ${ }^{25}$ Reasons for this remain unknown, although Black patients have an android shaped pelvis, which are taller and narrower possibly making apical dissection, a common site for PSM, more challenging. However, is also likely that Black patients have access to poorer quality care which may explain this disparity in surgical outcome. ${ }^{10,26}$

Limitations in our study should be taken into account when interpreting the results. NCDB data collection is retrospective in nature. Data collected were from CoC 
362

hospitals which are often larger tertiary hospitals and these findings may not be generalised to smaller group practices. Nevertheless, NCDB captures over $50 \%$ of patients diagnosed with prostate cancer providing good representation of the United States. We also do not have details on tumour anatomical location following radical prostatectomy to determine if the higher risk of PSM in Black men was due to higher proportion of apical cancers. Additionally, we do not have details about the preoperative decision to perform a nerve-spare approach which may increase the likelihood of a PSM. The use of intraoperative frozen section when performing nervesparing cannot be determine and this is an important consideration as this has been shown to reduce PSM. ${ }^{27}$ There is also a lack of data on the length of PSM which has been shown to be an independent factor to biochemical recurrence. ${ }^{28}$ Finally, while hospital case volume is reported, we cannot determine individual surgeon case volume.

\section{Conclusion}

There is significant variation in PSM following radical prostatectomy for pT2 disease. Patient-specific, hospital-specific and cancer-specific factors contributed 2.3\%, 3.9\% and $15.2 \%$ to the variation in PSM in pT2 patients respectively. A total of $84.8 \%$ of PSM variation due to patient, hospital and other factors not accounted for in the model. Non cancer-specific factors represent potentially addressable factors which are important for policy makers in their efforts to improve patient outcomes.

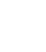

4

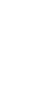

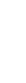

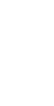

8




\section{Clinical Practice Points (179/250 words):}

- Positive surgical margin (PSM) following radical prostatectomy for pT2 prostate cancer is considered a metric for surgical quality. However, there is significant variation in PSM rates.

- In this study, we examined contemporary PSM rates in the United States using the National Cancer Data Base (NCDB) registry and used a multivariable mixed-effects model to estimate the association between PSM and patient demographics, socioeconomic, geographical, hospital, cancerspecific and surgical approach factors.

- We report that robotic and laparoscopic surgical approach, academic institution and high hospital surgical volume were independently associated with a lower PSM. Black men and adverse cancer specific features (PSA 1020, PSA >20, cT3 stage, Gleason 7, 8, 9-10; all p>0.01) were independently associated with a higher PSM.

- The overall mixed effects logistic regression model accounted for $24.9 \%$ of PSM variation. Patient-specific, hospital-specific and cancer-specific factors had a contribution of $2.3 \%, 3.9 \%$ and $15.6 \%$ to the variation in PSM. Facility had a contribution of $23.7 \%$ to the variation in PSM.

- Non cancer-specific factors represent potentially addressable factors which are important for policy makers in their efforts to improve patient outcome.

Acknowledgments: Quoc-Dien Trinh supported by the Brigham Research Institute Fund to Sustain Research Excellence, the Bruce A. Beal and Robert L. Beal Surgical Fellowship, the Genentech BioOncology Career Development Award from the Conquer Cancer Foundation of the American Society of Clinical Oncology, a Health Services Research pilot test grant from the Defense Health Agency, the Clay Hamlin Young Investigator Award from the Prostate Cancer Foundation, and an unrestricted educational grant from the Vattikuti Urology Institute. Wei Shen Tan is supported by grants from The Urology Foundation and The Mason Medical Research Trust both from the UK. Sebastian Berg is supported by a grant from the German Research Foundation. 
424 Financial disclosures: Quoc-Dien Trinh certifies that all conflicts of interest, 425 including specific financial interests and relationships and affiliations relevant to the 426 subject matter or materials discussed in the manuscript (eg, employment/affiliation, 427 grants or funding, consultancies, honoraria, stock ownership or options, expert 428 testimony, royalties, or patents filed, received, or pending), are the following: Quoc429 Dien Trinh reports honoraria from Bayer and Astellas and research funding from 430 Intuitive Surgical. Wei Shen Tan is a consultant for Combat Medical. Toni K. Choueiri 431 is a consultant/advisory board member for Bayer, Bristol-Myers Squibb, Exelixis, 432 Merck, Novartis, Peloton, Pfizer and Roche. Adam S Kibel reports consulting fees 433 from Sanofi and Profound Medical. 
451 Tables:

452 Table 1: Baseline patient demographics, socioeconomic, geographical, hospital and 453 cancer-specific factors stratified according to positive surgical margin (PSM) status.

454 Table 2: Multilevel Hierarchical Mixed Effects Logistic Regression Model to 455 determine variables independently associated with a PSM in pT2 prostate cancer 456 patients treated with radical prostatectomy.

457 Table 3: Multilevel hierarchical logistic regression model to determine pseudo-R2458 values and significance of patient, hospital and cancer-specific variables.

Figures:

462 Figure 1: Inclusion and exclusion criteria used to determine study cohort.

463 Figure 2: Variation in PSM frequency adjusted for patient demographics, 
482

Table 1: Baseline patient demographics, socioeconomic, geographical, hospital and cancer-specific variables stratified according to positive surgical margin (PSM) status.

\begin{tabular}{|c|c|c|c|c|}
\hline & $\begin{array}{l}\text { All patients } \\
(n=45,426)\end{array}$ & $\begin{array}{l}\text { Positive } \\
\text { surgical } \\
\text { margin } \\
(p=4,522)\end{array}$ & $\begin{array}{c}\text { No positive } \\
\text { surgical margin } \\
(n=40,904)\end{array}$ & $P$ value \\
\hline $\begin{array}{l}\text { Age at diagnosis, } \mathbf{n}(\%) \\
32-56 \mathrm{yr} \\
57-61 \mathrm{yr} \\
62-66 \mathrm{yr} \\
67-90 \mathrm{yr}\end{array}$ & $\begin{array}{l}12,167(26.8) \\
10,662(23.4) \\
11,537(25.4) \\
11,060(24.4)\end{array}$ & $\begin{array}{l}1,223(27.1) \\
1,021(22.6) \\
1,188(26.3) \\
1,090(24.1)\end{array}$ & $\begin{array}{c}10,994(26.7) \\
9,641(23.6) \\
10,349(25.3) \\
9,970(24.4)\end{array}$ & 0.325 \\
\hline $\begin{array}{l}\text { Race, } \mathbf{n}(\%) \\
\text { White } \\
\text { Black } \\
\text { Other } \\
\text { Unknown }\end{array}$ & $\begin{array}{c}38,729(85.3) \\
4,699(10.3) \\
1,392(3.1) \\
606(1.3) \\
\end{array}$ & $\begin{array}{c}3,800(84.0) \\
543(12.0) \\
119(2.6) \\
60(1.4) \\
\end{array}$ & $\begin{array}{c}34,929(85.4) \\
4,156(10.2) \\
1,273(3.1) \\
546(1.3) \\
\end{array}$ & 0.001 \\
\hline $\begin{array}{l}\text { Charlson Comorbidity Index, } \mathbf{n}(\%) \\
0 \\
1 \\
>1\end{array}$ & $\begin{array}{c}37,738(83.1) \\
6,643(14.6) \\
1,045(2.3)\end{array}$ & $\begin{array}{c}3,718(82.2) \\
702(15.5) \\
102(2.3)\end{array}$ & $\begin{array}{c}34,020(83.2) \\
5,941(14.5) \\
943(2.3)\end{array}$ & 0.195 \\
\hline $\begin{array}{l}\text { Prostate specific antigen at diagnosis } \mathbf{n g} / \mathbf{~ m L}, \mathbf{n}(\%) \\
<10 \\
10-20 \\
>20 \\
\text { Unknown }\end{array}$ & $\begin{array}{c}33,009(72.7) \\
3,436(7.6) \\
1,582(3.5) \\
7,399(16.3) \\
\end{array}$ & $\begin{array}{c}3,309(73.2) \\
415(9.2) \\
212(4.7) \\
586(13.0) \\
\end{array}$ & $\begin{array}{c}29,700(72.6) \\
3,021(7.39) \\
1,370(3.4) \\
6,813(16.6) \\
\end{array}$ & $<0.001$ \\
\hline $\begin{array}{l}\text { Clinical T stage, } \mathbf{n}(\%) \\
\text { cT1 } \\
\text { cT2 } \\
\text { cT3-4 } \\
\text { Unknown }\end{array}$ & $\begin{array}{c}1,120(2.5) \\
39,773(87.6) \\
668(1.5) \\
3,865(8.5)\end{array}$ & $\begin{array}{c}88(2.0) \\
4,020(88.9) \\
91(2.0) \\
323(7.1)\end{array}$ & $\begin{array}{c}1,032(2.5) \\
35,753(87.4) \\
577(1.4) \\
3,542(8.7)\end{array}$ & $<0.001$ \\
\hline $\begin{array}{l}\text { Gleason score, } \mathbf{n}(\%) \\
\leq 6 \\
7 \\
8 \\
9-10 \\
\text { Unknown }\end{array}$ & $\begin{array}{c}19,408(43.7) \\
15,675(34.5) \\
2,537(5.6) \\
851(1.9) \\
6,995(15.3) \\
\end{array}$ & $\begin{array}{l}1,577(34.9) \\
1,913(42.3) \\
296(6.6) \\
118(2.6) \\
618(13.6) \\
\end{array}$ & $\begin{array}{c}17,831(43.6) \\
13,762(33.6) \\
2,241(5.5) \\
733(1.8) \\
6,337(15.5) \\
\end{array}$ & $<0.001$ \\
\hline $\begin{array}{l}\text { Year of diagnosis, } \mathbf{n}(\%) \\
2010 \\
2011 \\
2012 \\
2013 \\
2014 \\
2015\end{array}$ & $\begin{array}{l}9,844(21.7) \\
9,675(21.3) \\
7,312(16.1) \\
6,837(15.0) \\
5,966(13.1) \\
5,792(12.8)\end{array}$ & $\begin{array}{l}981(21.7) \\
958(21.2) \\
711(15.7) \\
621(13.7) \\
617(13.7) \\
634(14.0)\end{array}$ & $\begin{array}{l}8,863(21.7) \\
8,717(21.3) \\
6,601(16.1) \\
6,216(15.2) \\
5,349(13.1) \\
5,158(12.6)\end{array}$ & 0.018 \\
\hline $\begin{array}{l}\text { Surgical approach, } \mathbf{n}(\%) \\
\text { Open } \\
\text { Laparoscopic } \\
\text { Robotic } \\
\text { Unknown }\end{array}$ & $\begin{array}{c}8,890(19.6) \\
1,882(4.1) \\
33,347(73.4) \\
1,307(2.9) \\
\end{array}$ & $\begin{array}{c}945(20.9) \\
159(3.5) \\
3,240(71.7) \\
178(3.94) \\
\end{array}$ & $\begin{array}{c}7,945(19.4) \\
1,723(4.2) \\
30,107(73.6) \\
1,129(2.8) \\
\end{array}$ & $<0.001$ \\
\hline $\begin{array}{l}\text { Insurance status, } \mathbf{n}(\%) \\
\text { Private } \\
\text { Medicaid } \\
\text { Medicare } \\
\text { Other government } \\
\text { Uninsured } \\
\text { Unknown } \\
\end{array}$ & $\begin{array}{c}28,557(62.9) \\
827(1.8) \\
14,088(31.0) \\
714(1.6) \\
582(1.3) \\
658(1.5) \\
\end{array}$ & $\begin{array}{l}2,810(62.1) \\
91(2.0) \\
1,407(31.1) \\
75(1.7) \\
75(1.7) \\
64(1.4) \\
\end{array}$ & $\begin{array}{l}25,747(62.9) \\
736(1.8) \\
12,681(31.0) \\
639(1.6) \\
507(1.2) \\
594(1.5) \\
\end{array}$ & 0.199 \\
\hline $\begin{array}{l}\text { Median income quartiles within ZIP code, } \mathbf{n}(\%) \\
\geq \$ 63,000 \\
\$ 48,000-\$ 62,999 \\
\$ 38,000-\$ 47,999 \\
\leq \$ 37,999 \\
\text { Unknown }\end{array}$ & $\begin{array}{c}17,849(39.3) \\
12,434(27.4) \\
9,305(20.5) \\
5,727(12.6) \\
111(0.2) \\
\end{array}$ & $\begin{array}{c}1,691(37.4) \\
1,251(27.7) \\
956(21.1) \\
605(13.4) \\
19(0.4)\end{array}$ & $\begin{array}{c}16,158(39.5) \\
11,183(27.3) \\
8,349(20.4) \\
5,122(12.5) \\
92(0.2)\end{array}$ & 0.006 \\
\hline
\end{tabular}




\begin{tabular}{|c|c|c|c|c|}
\hline $\begin{array}{l}\text { Percentages of no high school degree, } \mathbf{n}(\%) \\
\geq 21 \% \\
13-20.9 \% \\
7-12.9 \% \\
\leq 6.9 \% \\
\text { Unknown }\end{array}$ & $\begin{array}{l}5,628(12.4) \\
10,219(22.5) \\
15,084(33.2) \\
14,398(31.7) \\
\quad 97(0.2)\end{array}$ & $\begin{array}{c}603(13.2) \\
1,003(22.2) \\
1,553(34.3) \\
1,345(29.7) \\
18(0.4)\end{array}$ & $\begin{array}{c}5,025(12.3) \\
9,216(22.5) \\
13,531(33.1) \\
13,053(31.9) \\
79(0.2)\end{array}$ & 0.001 \\
\hline $\begin{array}{l}\text { Urban/ rural status of county, } \mathbf{n}(\%) \\
\text { Metropolitan } \\
\text { Urban } \\
\text { Rural } \\
\text { Unknown }\end{array}$ & $\begin{array}{l}37,148(81.8) \\
6,267(13.8) \\
885(2.0) \\
1,126(2.5)\end{array}$ & $\begin{array}{l}3,664(81.0) \\
649(14.4) \\
92(2.0) \\
117(2.6)\end{array}$ & $\begin{array}{c}33,484(81.9) \\
5,618(13.7) \\
793(1.9) \\
1,009(2.5)\end{array}$ & 0.593 \\
\hline $\begin{array}{l}\text { Great circle distance, } \mathbf{n}(\%) \\
<6.3 \text { miles } \\
6.3-13.9 \text { miles } \\
14-35.6 \text { miles } \\
>35.6 \text { miles }\end{array}$ & $\begin{array}{l}11,197(24.7) \\
11,388(25.1) \\
11,399(25.2) \\
11,338(25.0)\end{array}$ & $\begin{array}{l}1,215(27.0) \\
1,156(25.7) \\
1,144(25.4) \\
986(21.9)\end{array}$ & $\begin{array}{c}9,982(24.5) \\
10,232(25.1) \\
10,255(25.1) \\
10,352(25.4)\end{array}$ & $<0.001$ \\
\hline $\begin{array}{l}\text { Treating hospital, } \mathbf{n}(\%) \\
\text { Comprehensive community cancer programme } \\
\text { Community cancer programme } \\
\text { Integrated Network Cancer Programme } \\
\text { Academic }\end{array}$ & $\begin{array}{c}18,705(41.2) \\
2,474(5.5) \\
5,034(11.1) \\
19,148(42.2) \\
\end{array}$ & $\begin{array}{c}2,001(44.3) \\
307(6.8) \\
613(13.6) \\
1,594(35.3) \\
\end{array}$ & $\begin{array}{c}16,704(40.9) \\
2,167(5.3) \\
4,421(10.8) \\
17,554(43.0) \\
\end{array}$ & $<0.001$ \\
\hline $\begin{array}{l}\text { Hospital surgical volume, } \mathbf{n}(\%) \\
<89 \text { cases } \\
89-163 \text { cases } \\
164-296 \text { cases } \\
>297 \text { cases }\end{array}$ & $\begin{array}{l}10,098(22.2) \\
11,380(25.1) \\
11,554(25.4) \\
12,394(27.3) \\
\end{array}$ & $\begin{array}{c}1,158(25.6) \\
1,245(27.5) \\
1,181(26.1) \\
938(20.7) \\
\end{array}$ & $\begin{array}{c}8,940(21.9) \\
10,135(24.8) \\
10,373(25.4) \\
11,456(28.01)\end{array}$ & $<0.001$ \\
\hline $\begin{array}{l}\text { Census division of treatment facility, } \mathbf{n}(\%) \\
\text { New England } \\
\text { Middle Atlantic } \\
\text { South Atlantic } \\
\text { East North Central } \\
\text { East South Central } \\
\text { West North Central } \\
\text { West South Central } \\
\text { Mountain } \\
\text { Pacific }\end{array}$ & $\begin{array}{c}2,058(4.5) \\
7,226(15.9) \\
9,282(20.5) \\
7,865(17.3) \\
3,895(8.6) \\
4,530(10.0) \\
3,434(7.6) \\
2,060(4.5) \\
5,011(11.1)\end{array}$ & $\begin{array}{c}202(4.5) \\
697(15.4) \\
917(20.3) \\
769(17.1) \\
305(6.8) \\
462(10.2) \\
358(7.9) \\
272(6.0) \\
533(11.8)\end{array}$ & $\begin{array}{c}1,856(4.5) \\
6,529(16.0) \\
8,365(20.5) \\
7,096(17.4) \\
3,590(8.8) \\
4,068(10.0) \\
3,076(7.5) \\
1,788(4.3) \\
4,478(11.0)\end{array}$ & $<0.001$ \\
\hline
\end{tabular}

485

486

487

488

489

490

491

492

493

494

495

496

497

498 
Table 2: Multilevel Hierarchical Mixed Effects Logistic Regression Model to determine variables independently associated with a positive surgical margin in pT2 prostate cancer patients treated with radical prostatectomy.

\begin{tabular}{|c|c|c|c|}
\hline Variables & Odds ratio & $95 \% \mathrm{Cl}$ & P value \\
\hline \multicolumn{4}{|l|}{ Patient-specific } \\
\hline \multicolumn{4}{|l|}{ Age at diagnosis } \\
\hline $57-61 \mathrm{yr}$ & 0.91 & 0.83-0.99 & 0.031 \\
\hline $62-66 \mathrm{yr}$ & 0.96 & $0.88-1.05$ & 0.389 \\
\hline $67-90 \mathrm{yr}$ & 0.92 & $0.82-1.03$ & 0.146 \\
\hline \multicolumn{4}{|l|}{ Year of diagnosis } \\
\hline $\begin{array}{l}2010 \\
2011\end{array}$ & 0.98 & 0.89-1.08 & 0.620 \\
\hline 2012 & 0.93 & $0.84-1.04$ & 0.209 \\
\hline 2013 & 0.84 & $0.75-0.94$ & 0.003 \\
\hline 2014 & 0.95 & $0.85-1.07$ & 0.416 \\
\hline 2015 & 0.98 & 0.87-1.09 & 0.685 \\
\hline \multirow{2}{*}{\multicolumn{4}{|c|}{$\begin{array}{l}\text { Race } \\
\text { White }\end{array}$}} \\
\hline & & & \\
\hline Black & 1.13 & $1.01-1.26$ & 0.024 \\
\hline Other & 0.86 & $0.70-1.05$ & 0.132 \\
\hline Unknown & 0.96 & $0.72-1.28$ & 0.787 \\
\hline \multirow{2}{*}{\multicolumn{4}{|c|}{$\begin{array}{l}\text { Charlson Comorbidity Index } \\
0\end{array}$}} \\
\hline & & & \\
\hline 1 & 1.06 & $0.97-1.15$ & 0.238 \\
\hline$>1$ & 0.95 & $0.77-1.18$ & 0.672 \\
\hline \multicolumn{4}{|l|}{ Insurance status } \\
\hline Private & & & \\
\hline Medicaid & 1.02 & $0.80-1.29$ & 0.892 \\
\hline Medicare & 0.98 & $0.89-1.08$ & 0.716 \\
\hline Other governmen & 0.97 & $0.75-1.24$ & 0.800 \\
\hline Uninsured & 1.24 & $0.95-1.63$ & 0.109 \\
\hline Unknown & 1.00 & $0.75-1.34$ & 1.000 \\
\hline \multirow{2}{*}{\multicolumn{4}{|c|}{$\begin{array}{l}\text { Median income quartiles within ZIP code } \\
\geq \$ 63,000\end{array}$}} \\
\hline & & & \\
\hline$\$ 48,000-\$ 62,999$ & 1.03 & $0.94-1.13$ & 0.555 \\
\hline$\$ 38,000-\$ 47,999$ & 1.06 & $0.94-1.19$ & 0.349 \\
\hline$\leq \$ 37,999$ & 1.11 & $0.95-1.29$ & 0.187 \\
\hline Unknown & 0.72 & $0.09-5.82$ & 0.756 \\
\hline \multirow{2}{*}{\multicolumn{4}{|c|}{$\begin{array}{l}\text { Percentage of no high school degree } \\
\geq 21 \%\end{array}$}} \\
\hline & & & \\
\hline $\begin{array}{l}13-20.9 \% \\
7-12.9 \%\end{array}$ & 1.02 & $0.89-1.16$ & 0.802 \\
\hline$\leq 6.9 \%$ & 0.93 & $0.80-1.08$ & 0.348 \\
\hline Unknown & 1.09 & $0.08-14.29$ & 0.948 \\
\hline \multicolumn{4}{|c|}{ Urban/ rural status of county } \\
\hline Metropolitan & & & \\
\hline Urban & 1.03 & $0.92-1.16$ & 0.577 \\
\hline Rural & 1.01 & $0.79-1.29$ & 0.931 \\
\hline Unknown & 1.03 & $0.82-1.27$ & 0.816 \\
\hline \multicolumn{4}{|c|}{ Great circle distance } \\
\hline$<6.3$ miles & & & \\
\hline $\begin{array}{l}\text { 6.3-13.9 miles } \\
14-35.6 \text { miles }\end{array}$ & 1.01 & $0.92-1.10$ & $\begin{array}{l}0.9 / 0 \\
0.740\end{array}$ \\
\hline$>35.6$ miles & 0.98 & $0.88-1.10$ & 0.781 \\
\hline \multicolumn{4}{|l|}{ Cancer specific } \\
\hline \multirow{2}{*}{\multicolumn{4}{|c|}{$\begin{array}{l}\text { Prostate specific antigen } \\
<10\end{array}$}} \\
\hline & & & \\
\hline $10-20$ & 1.18 & $1.05-1.32$ & 0.004 \\
\hline$>20$ & 1.36 & $1.16-1.59$ & $<0.001$ \\
\hline Unknown & 0.80 & $0.72-0.89$ & $<0.001$ \\
\hline \multicolumn{4}{|l|}{$\begin{array}{l}\text { Clinical T stage } \\
\text { cT1 }\end{array}$} \\
\hline $\begin{array}{l}\text { cT1 } \\
\text { cT2 }\end{array}$ & 1.25 & $0.99-1.57$ & 0.060 \\
\hline
\end{tabular}




\begin{tabular}{|c|c|c|c|}
\hline $\begin{array}{l}\text { cT3-4 } \\
\text { Unknown }\end{array}$ & $\begin{array}{l}1.57 \\
1.11\end{array}$ & $\begin{array}{l}1.14-2.17 \\
0.86-1.42\end{array}$ & $\begin{array}{l}0.006 \\
0.438\end{array}$ \\
\hline \multicolumn{4}{|l|}{$\begin{array}{l}\text { Gleason score } \\
\leq 6\end{array}$} \\
\hline 7 & 1.61 & $1.49-1.73$ & $<0.001$ \\
\hline 8 & 1.48 & $1.28-1.69$ & $<0.001$ \\
\hline $9-10$ & 1.80 & $1.46-2.23$ & $<0.001$ \\
\hline Unknown & 1.19 & $1.06-1.35$ & 0.003 \\
\hline \multicolumn{4}{|l|}{ Hospital level variables } \\
\hline \multirow{2}{*}{\multicolumn{4}{|c|}{$\begin{array}{l}\text { Surgical approach } \\
\text { Open }\end{array}$}} \\
\hline & & & \\
\hline Robotic & 0.90 & 0.83-0.99 & 0.029 \\
\hline Laparoscopic & 0.74 & $0.62-0.90$ & 0.002 \\
\hline Unknown & 1.25 & $1.04-1.51$ & 0.018 \\
\hline \multirow{2}{*}{\multicolumn{4}{|c|}{$\begin{array}{l}\text { Treating hospital } \\
\text { Comprehensive community cancer programme }\end{array}$}} \\
\hline & & & \\
\hline Community cancer programme & 1.17 & $0.98-1.40$ & 0.079 \\
\hline Integrated Network Cancer Programme & 1.08 & $0.91-1.28$ & 0.378 \\
\hline Academic & 0.87 & $0.76-1.00$ & 0.044 \\
\hline \multicolumn{4}{|l|}{ Hospital surgical volume } \\
\hline $\begin{array}{l}<89 \text { cases } \\
89-163 \text { cases }\end{array}$ & & & \\
\hline $\begin{array}{l}89-163 \text { cases } \\
164-296 \text { cases }\end{array}$ & 0.07 & $0.81-1.05$ & 0.240 \\
\hline $\begin{array}{l}164-296 \text { cases } \\
>297 \text { cases }\end{array}$ & 0.83 & $0.70-0.99$ & 0.038 \\
\hline \multirow{2}{*}{\multicolumn{4}{|c|}{$\begin{array}{l}\text { Census division of treatment facility } \\
\text { New England }\end{array}$}} \\
\hline & & & \\
\hline Middle Atlantic & 1.05 & $0.81-1.36$ & 0.729 \\
\hline South Atlantic & 0.93 & $0.72-1.20$ & 0.576 \\
\hline East North Central & 1.02 & $0.79-1.31$ & 0.867 \\
\hline East South Central & 0.71 & $0.52-0.96$ & 0.025 \\
\hline West North Central & 1.03 & $0.78-1.37$ & 0.833 \\
\hline West South Central & 1.04 & $0.78-1.39$ & 0.789 \\
\hline Mountain & 1.36 & $1.00-1.85$ & 0.053 \\
\hline Pacific & 1.10 & $0.85-1.44$ & 0.463 \\
\hline
\end{tabular}

502 
Table 3: Multilevel hierarchical logistic regression model to determine pseudo-R2- values and significance of patient, hospital and cancer-specific variables.

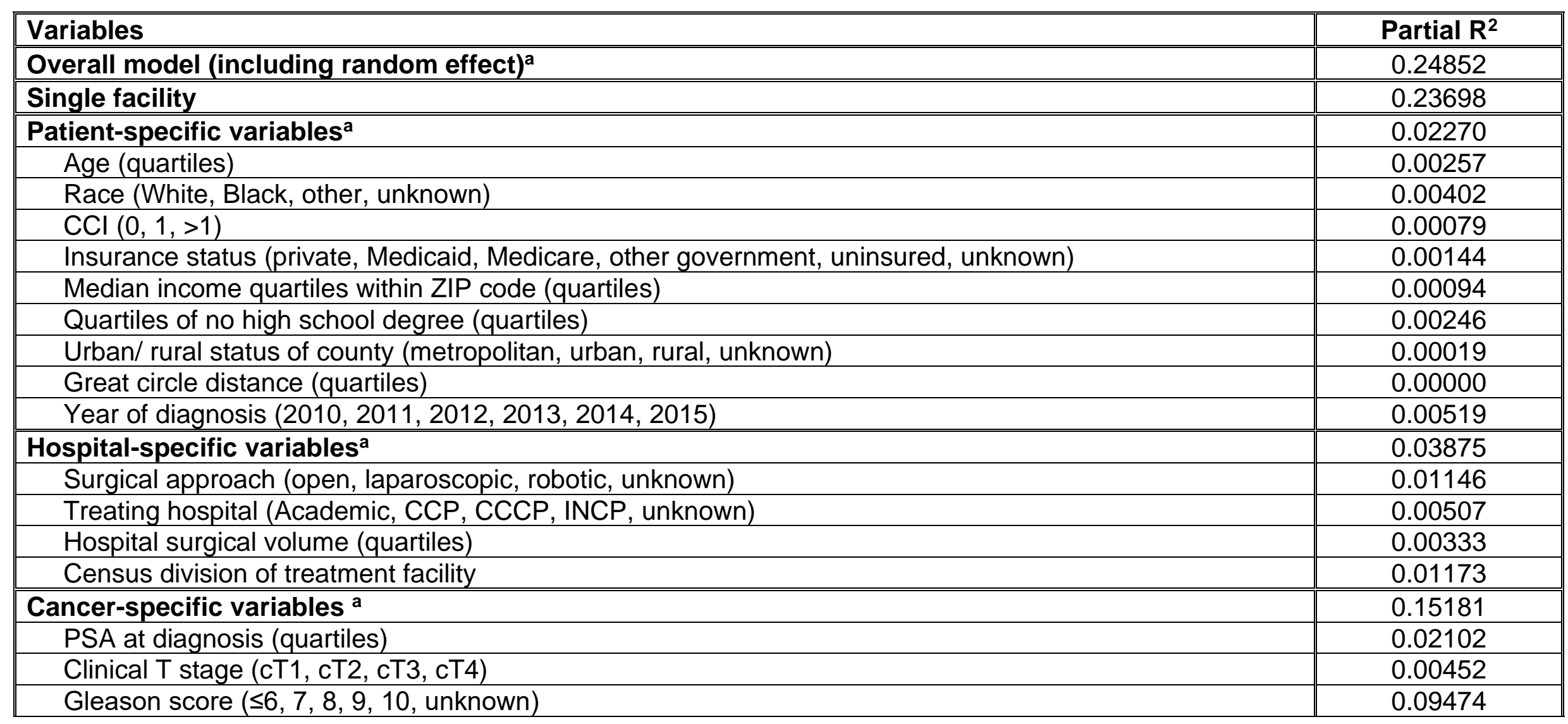

aRandom effect model 
Figure 1: Inclusion and exclusion criteria used to determine study cohort.

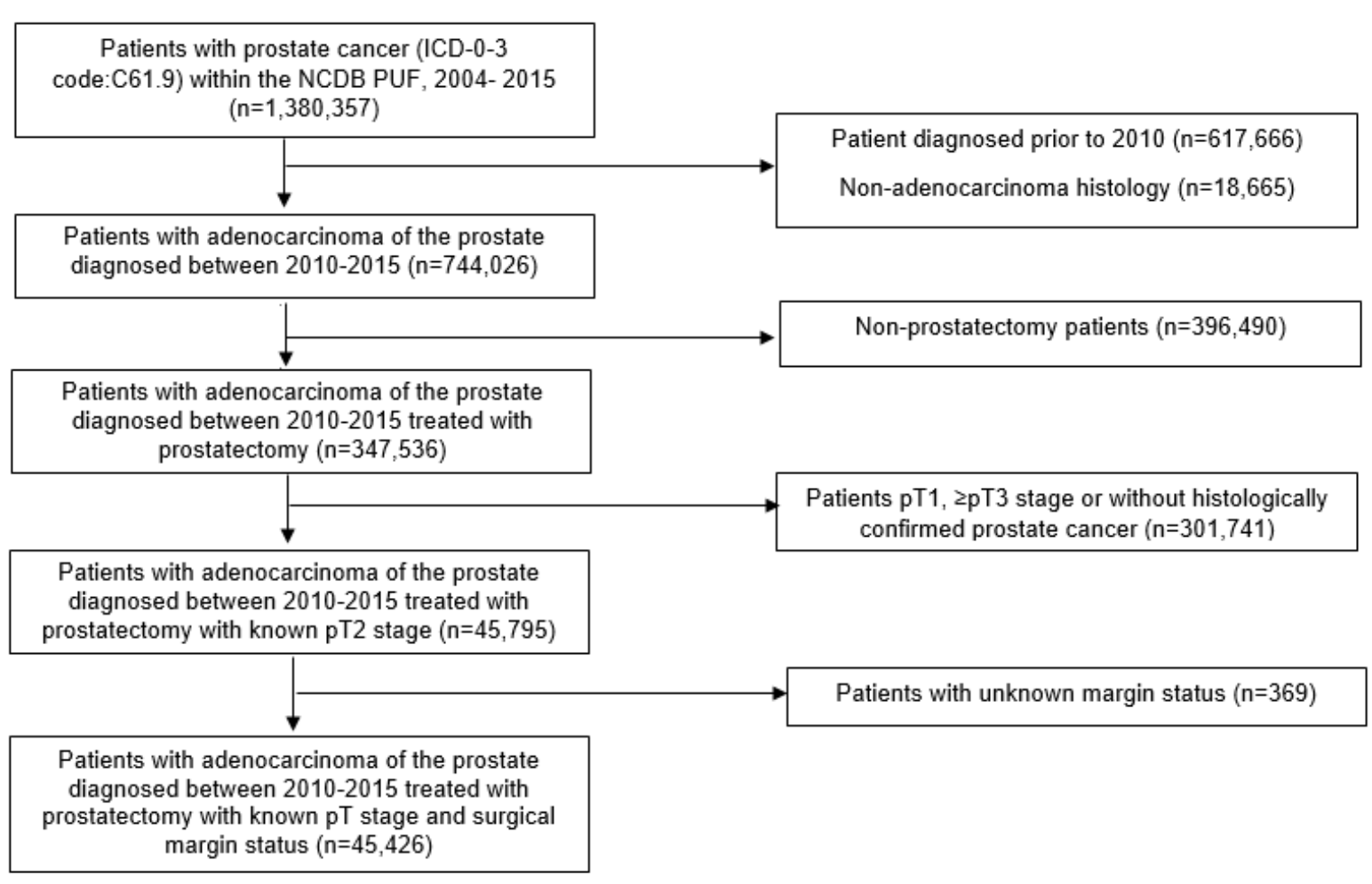


Figure 2: Variation in positive surgical margins frequency adjusted for patient demographics, comorbidity, socioeconomic, geographical, hospital and cancer-specific factors.

Figure 2: Variability in Risk-adjusted Probability of Positive Surgical Margin

Following Radical Prostatectomy in pT2 Disease

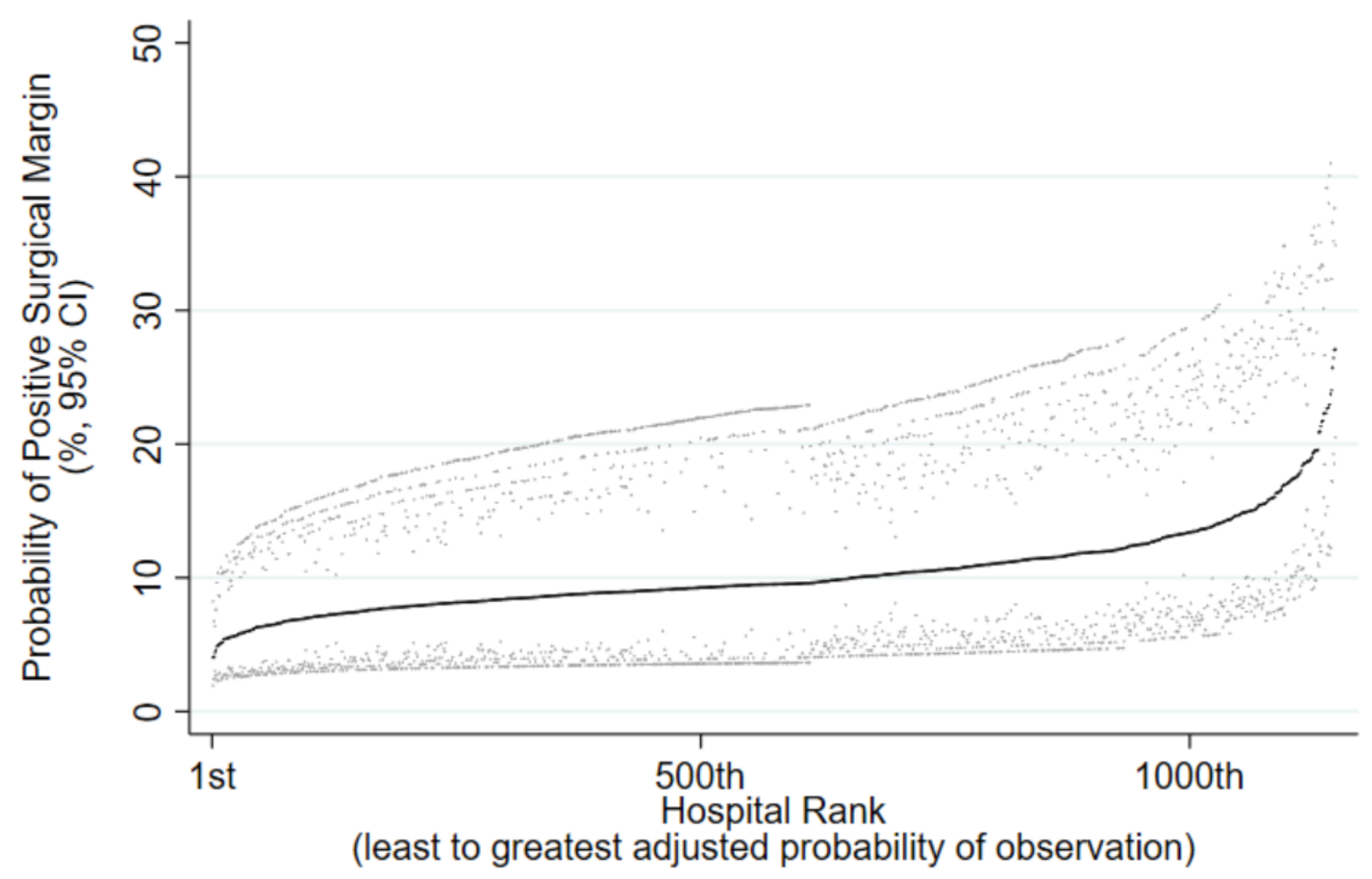




\section{References}

1. Yossepowitch O, Briganti A, Eastham JA, et al. Positive surgical margins after radical prostatectomy: a systematic review and contemporary update. Eur Urol. 2014;65:303-313.

2. Bolla $M$, van Poppel $H$, Tombal $B$, et al. Postoperative radiotherapy after radical prostatectomy for high-risk prostate cancer: long-term results of a randomised controlled trial (EORTC trial 22911). Lancet. 2012;380:2018-2027.

3. Damani A, Van Hemelrijck M, Wulaningsih W, Crawley D, Cahill D. Are you now a good surgeon? T2 positive margin status as a quality outcome measure following radical prostatectomy. World J Urol. 2017;35:35-43.

4. Tewari A, Sooriakumaran P, Bloch DA, Seshadri-Kreaden U, Hebert AE, Wiklund P. Positive surgical margin and perioperative complication rates of primary surgical treatments for prostate cancer: a systematic review and meta-analysis comparing retropubic, laparoscopic, and robotic prostatectomy. Eur Urol. 2012;62:1-15.

5. Novara G, Ficarra V, Mocellin S, et al. Systematic review and meta-analysis of studies reporting oncologic outcome after robot-assisted radical prostatectomy. Eur Urol. 2012;62:382-404.

6. Preston MA, Breau RH, Lantz AG, et al. The association between nerve sparing and a positive surgical margin during radical prostatectomy. Urol Oncol. 2015;33:18.e11-18.e16.

7. Eastham JA, Kattan MW, Riedel E, et al. Variations among individual surgeons in the rate of positive surgical margins in radical prostatectomy specimens. J Urol. 2003;170:2292-2295.

8. Borin JF, Skarecky DW, Narula N, Ahlering TE. Impact of urethral stump length on continence and positive surgical margins in robot-assisted laparoscopic prostatectomy. Urology. 2007;70:173-177.

9. Yaxley JW, Coughlin GD, Chambers SK, et al. Robot-assisted laparoscopic prostatectomy versus open radical retropubic prostatectomy: early outcomes from a randomised controlled phase 3 study. Lancet. 2016;388:1057-1066.

10. Schmid M, Meyer CP, Reznor G, et al. Racial differences in the surgical care of medicare beneficiaries with localized prostate cancer. JAMA oncology. 2016;2:85-93.

11. Löppenberg B, Friedlander DF, Krasnova A, et al. Variation in the use of active surveillance for low-risk prostate cancer. Cancer. 2018;124:55-64.

12. Winchester DP, Stewart AK, Bura C, Jones RS. The National Cancer Data Base: a clinical surveillance and quality improvement tool. J Surg Oncol. 2004;85:1-3.

13. Bilimoria KY, Stewart AK, Winchester DP, Ko CY. The National Cancer Data Base: a powerful initiative to improve cancer care in the United States. Ann Surg Oncol. 2008;15:683-690.

14. April F, Constance P, Andrew J, Kanagaratnam S, Leslie S, Max P. International Classification of Diseases for Oncology (ICD-O): Geneva: World Health Organization; 2000.

15. Mohler JL, Kantoff PW, Armstrong AJ, et al. Prostate cancer, version 2.2014. Journal of the National Comprehensive Cancer Network. 2014;12:686-718.

16. Frederick L, Page DL, Fleming ID, et al. AJCC cancer staging manual: Springer Science \& Business Media; 2002.

17. Rao JN, Scott AJ. On chi-squared tests for multiway contingency tables with cell proportions estimated from survey data. The Annals of statistics. 1984:46-60.

18. Natarajan S, Lipsitz SR, Fitzmaurice GM, et al. An extension of the Wilcoxon rank sum test for complex sample survey data. Journal of the Royal Statistical Society: Series C (Applied Statistics). 2012;61:653-664.

19. Sheetz $\mathrm{KH}$, Dimick JB, Ghaferi AA. The association between hospital care intensity and surgical outcomes in medicare patients. JAMA surgery. 2014;149:1254-1259.

20. Chang SL, Kibel AS, Brooks JD, Chung BI. The impact of robotic surgery on the surgical management of prostate cancer in the USA. BJU Int. 2015;115:929-936. 
21. Atug F, Castle EP, Srivastav SK, Burgess SV, Thomas R, Davis R. Positive surgical margins in robotic-assisted radical prostatectomy: impact of learning curve on oncologic outcomes. european urology. 2006;49:866-872.

22. Cross CK, Shultz D, Malkowicz SB, et al. Impact of race on prostate-specific antigen outcome after radical prostatectomy for clinically localized adenocarcinoma of the prostate. J Clin Oncol. 2002;20:2863-2868.

23. Freedland SJ, Dorey F, Aronson WJ. Multivariate analysis of race and adverse pathologic findings after radical prostatectomy. Urology. 2000;56:807-811.

24. Witte MN, Kattan MW, Albani J, Sharp DS, Eastham JA, Morton RA, Jr. Race is not an independent predictor of positive surgical margins after radical prostatectomy. Urology. 1999;54:869-874.

25. Jalloh M, Myers F, Cowan JE, Carroll PR, Cooperberg MR. Racial variation in prostate cancer upgrading and upstaging among men with low-risk clinical characteristics. Eur Urol. 2015;67:451-457.

26. Mahal BA, Ziehr DR, Aizer AA, et al. Getting back to equal: the influence of insurance status on racial disparities in the treatment of African American men with high-risk prostate cancer. Urologic Oncology: Seminars and Original Investigations. Vol 32: Elsevier; 2014:1285-1291.

27. Beyer B, Schlomm T, Tennstedt P, et al. A feasible and time-efficient adaptation of NeuroSAFE for da Vinci robot-assisted radical prostatectomy. Eur Urol. 2014;66:138-144.

28. Shikanov S, Song J, Royce $C$, et al. Length of positive surgical margin after radical prostatectomy as a predictor of biochemical recurrence. J Urol. 2009;182:139-144. 